\title{
Association of neuromuscular reversal by sugammadex and neostigmine with 90-day mortality after non-cardiac surgery
}

\author{
Tak Kyu Oh${ }^{1}$, Jung-Hee Ryu ${ }^{1,2}$, Sunwoo Nam ${ }^{1}$ and Ah-Young Oh ${ }^{1,2^{*}}$ (D)
}

\begin{abstract}
Background: Reversing a neuromuscular blockade agent with sugammadex is known to lessen postoperative complications by reducing postoperative residual curarization. However, its effects on 90-day mortality are unknown. Therefore, this study aimed to compare the effects of sugammadex and neostigmine in terms of 90-day mortality after non-cardiac surgery.

Methods: This retrospective cohort study analyzed the medical records of adult patients aged 18 years or older who underwent non-cardiac surgery at a single tertiary care hospital between 2011 and 2016. Propensity score matching and Cox regression analysis were used to investigate the effectiveness of sugammadex and neostigmine in lowering 90-day mortality after non-cardiac surgery.

Results: A total of 65,702 patients were included in the analysis (mean age: 52.3 years, standard deviation: 15.7), and 23,532 of these patients (35.8\%) received general surgery. After propensity score matching, 14,179 patients (3906 patients from the sugammadex group and 10,273 patients from the neostigmine group) were included in the final analysis. Cox regression analysis in the propensity score-matched cohort showed that the risk of 90-day mortality was $40 \%$ lower in the sugammadex group than in the neostigmine group (hazard ratio: 0.60, 95\% confidence interval: $0.37,0.98 ; P=0.042$ ). These results were similar in the multivariable Cox regression analysis of the entire cohort (hazard ratio: $0.62,95 \%$ confidence interval: 0.39, 0.96; $P=0.036$ ).

Conclusions: This retrospective cohort study suggested that reversing rocuronium with sugammadex might be associated with lower 90-day mortality after non-cardiac surgery compared to neostigmine. However, since this study did not evaluate quantitative neuromuscular function in the postoperative period due to its retrospective design, the results should be interpreted carefully. Future prospective studies with quantitative neuromuscular monitoring in the postoperative period should be performed to confirm these results.
\end{abstract}

Keywords: Muscle relaxation, Mortality, Neostigmine, Sugammadex

\section{Background}

Neuromuscular blocking agents (NMBAs) have enabled anesthesiologists to achieve optimal surgical conditions, in which patients are immobilized more easily, using smaller amounts of inhaled or intravenous anesthetics [1]. Muscle relaxation with NMBAs has now become part of the classic triad of anesthesia, along with unconsciousness and

\footnotetext{
* Correspondence: ohahyoung@hanmail.net

${ }^{1}$ Department of Anesthesiology and Pain Medicine, Seoul National University Bundang Hospital, Seongnam, South Korea

${ }^{2}$ Department of Anesthesiology and Pain Medicine, Seoul National University College of Medicine, Seoul, South Korea
}

analgesia [2]. However, like most drugs, NMBAs may cause complications, such as postoperative residual curarization (PORC) [3]. PORC can increase respiratory complications, which may be life-threatening in the immediate postoperative period [4], with an incidence as high as $63.5 \%$, as found by Fortier et al., and $64.7 \%$ according to the research by Saager et al. [5, 6].

In 1954, Beecher et al. first reported that the use of NMBAs is associated with anesthesia-related mortality [7]. Since then, PORC has been shown to increase lifethreatening critical respiratory events in the immediate postoperative period [8, 9]. In 2017, Bronsert and

(c) The Author(s). 2020 Open Access This article is distributed under the terms of the Creative Commons Attribution 4.0 International License (http://creativecommons.org/licenses/by/4.0/), which permits unrestricted use, distribution, and 
colleagues reported that PORC, caused by large amounts of NMBAs, may increase 30-day mortality and overall allcause mortality after non-cardiac surgery [10], in addition to causing critical complications in the immediate postoperative period [4]. This showed that PORC may affect mortality over a relatively long term, as well as in the immediate postoperative period. However, their study primarily used the conventional NMBA reversal agent, neostigmine, and not sugammadex, a newer NMBA reversal agent. Sugammadex is a selective relaxant-binding agent that quickly and effectively reverses the effects of steroidal NMBAs, especially rocuronium and vecuronium [11-13]. Compared with neostigmine, sugammadex more substantially reduces PORC $[14,15]$, but its effects on postoperative mortality requires further investigation.

Therefore, this study aimed to compare the effects of sugammadex and neostigmine in terms of 90-day mortality after non-cardiac surgery. We hypothesized that using sugammadex for NMBA reversal would improve 90-day mortality after non-cardiac surgery. We thus investigated the 90-day mortality after non-cardiac surgery between sugammadex and neostigmine groups, and also investigated whether the dosage of sugammadex or neostigmine affected the 90-day mortality after non-cardiac surgery.

\section{Methods}

\section{Design and ethical statement}

This retrospective cohort study was approved by the institutional review board (IRB) of the Seoul National University Bundang Hospital (SNUBH) (Approval number: B1809-495-102, approval date: September 7, 2018). Considering the retrospective nature of the study, in which the medical records of patients who had already completed treatment were analyzed, the requirement for obtaining informed consent was waived by the IRB. This manuscript adheres to the applicable STROBE guidelines.

\section{Patients}

This study analyzed the medical records of adult patients aged 18 years or older who underwent non-cardiac surgery at SNUBH between January 2011 and December 2016. When a patient underwent two or more surgeries, only the final surgery was included in the analysis. Additionally, cases involving incomplete or missing medical records, non-general anesthesia, use of NMBAs other than rocuronium (e.g., cisatracurium), or no NMBA reversal after surgery were excluded from the analysis.

\section{Rocuronium reversal by sugammadex or neostigmine}

SNUBH has generally used rocuronium for general anesthesia in non-cardiac surgeries, while neostigmine or sugammadex has been used as the agent for NMBA reversal after the end of each surgery. There is no strict guideline in our institution to determine the agent (sugammadex or neostigmine) used for NMBA reversal. The decision for using sugammadex or neostigmine is made based on the judgment of the individual anesthesiologist according to the type of surgery, the surgery time, the underlying disease of the patients, and the amount of NMBA used. In most cases, the dosage of sugammadex or neostigmine for NMBA reversal was determined after qualitative (subjective) neuromuscular monitoring using two peripheral nerve stimulators (Innervator 252; Fisher \& Paykel Healthcare, New Zealand, and EZStim II, model ES400; Life-Tech International, Stafford, Texas). The residual degree of neuromuscular block from NMBA at emergence was measured after the end of surgery and before extubation. After NBMA reversal administration, the train-of-four (TOF) count was re-checked using the peripheral nerve stimulator to decide on the patient's readiness for safe extubation. The dosage of sugammadex was determined by depth of neuromuscular block at the end of surgery [16]; $2 \mathrm{mg} / \mathrm{kg}$ of sugammadex was administered when the TOF count was $\geq 1$, while $4 \mathrm{mg} / \mathrm{kg}$ of sugammadex was administered when the post-tetanic count (PTC) was $\geq 1$. When neostigmine was used, the maximum dose $(50 \mathrm{mcg} / \mathrm{kg})$ was administered for NMBA reversal if the TOF count was 1 [16]. If the TOF count was 2-4 at end of surgery, 30-40 $\mathrm{mcg} / \mathrm{kg}$ was administered for NMBA reversal in the neostigmine group. Additionally, glycopyrrolate was administered with neostigmine to prevent the cholinergic complications of neostigmine. Intraoperative qualitative neuromuscular monitoring was performed throughout the surgery at the discretion of the anesthesiologist. For the present study, we classified patients who were administered sugammadex for NMBA reversal as the sugammadex group and those who were administered neostigmine as the neostigmine group.

\section{Covariates}

Information regarding the patients' physical characteristics (age [years], sex, body mass index $\left[\mathrm{kg} / \mathrm{m}^{2}\right]$ ); socioeconomic status (insurance type [National Health Insurance program/Medical Aid Beneficiary program]); marital status (never married/married or living together/ divorced or separated/widowed); highest educational attainment (lower than high school/more than or equal to high school, lower than college/more than or equal to college); occupation (office worker/licensed job/house work/self-employed/student, military or laborer/unemployed); and preoperative comorbidities, such as American Society of Anesthesiologists (ASA) physical status, hypertension, diabetes mellitus, ischemic heart disease, cerebrovascular disease, liver disease (fatty liver, liver cirrhosis, and hepatitis), dyslipidemia, chronic kidney disease, and cancer were recorded. Additionally, operative characteristics such as data regarding surgery and 
anesthesia time (min), emergency surgery, year of surgery, type of non-cardiac surgery (general, thoracic, neuro or spine, orthopedic, plastic, ear-nose-throat, dental, ophthalmic, gynecologic, or urologic surgery), intraoperative rocuronium dosage $(\mathrm{mg})$, and intraoperative qualitative neuromuscular monitoring were collected. The patients in the Medical Aid Beneficiary program are those who are classified as having a low income, and most of their hospital charges are paid by the government. For patients in the National Health Insurance program, approximately two-thirds of hospital charges are covered by the government.

\section{Ninety-day mortality after surgery}

All cases of death within 90 days from the date of surgery were included in the 90-day mortality calculations. We obtained the exact dates of death, including for those patients who were lost to follow-up, from the Ministry of the Interior and Safety in South Korea as of December 31, 2017.

\section{Statistical analysis}

Patient characteristics are presented as mean with standard deviation or number with percentage. First, we performed 1:5 propensity score (PS) matching, a method used to reduce confounding effects in observational studies [17]. The Nearest-Neighbor method, without replacement, was used for PS and the matching caliper was set to 0.2. All covariates were included in the PS model, and logistic regression analysis was performed to calculate PSs, as a logistic model. To determine the balance between the two groups before and after PS matching, the absolute value of the standardized mean difference (ASD) was measured; ASD $<0.2$ was defined as well-balanced. After confirming that covariates were well-balanced between the sugammadex and neostigmine groups after PS matching, both Cox regression and logistic regression analyses were performed to investigate the hazard ratio (HR) and odds ratio (OR) with $95 \%$ confidence intervals (CIs) for 90-day mortality of the sugammadex group as compared to the neostigmine group in the PS-matched cohort.

Second, we performed uni- and multivariable Cox regression analyses to investigate whether the results from the PS-matched cohort would be generalizable to the entire cohort in our hospital. Despite this, an understanding is required of the association between sugammadex reversal and 90-day mortality with other important confounders, and not only in isolation. All covariates, except for duration of anesthesia were included in the multivariable Cox regression model to avoid multicollinearity with duration of surgery. A log minus log plot was used to determine whether the resulting model satisfied the central assumption of the Cox proportional hazards model. There was no multi-collinearity among all variables in the multivariable model with a variance inflation factor $<2.0$. Third, as a secondary sensitivity analysis, we performed multivariable Cox regression analysis to investigate whether the dosage of the two NMBA reversal agents (sugammadex and neostigmine) affected 90-day mortality in each group. The dosage of sugammadex and neostigmine was divided into four groups by quartiles, and all covariates were included in the multivariable Cox regression model (except for duration of surgery). All analyses were performed using the open-source statistical software $R$ (version 3.6.1 with $\mathrm{R}$ packages); statistical significance was set at $P<0.05$.

\section{Results}

\section{Patients}

Non-cardiac surgery was performed in 168,731 cases at our institution between January 2011 and December 2016. Of these, 41,559 cases were initially excluded from analysis as two or more surgeries were performed in one patient during the study period; only the final surgery of each patient was included in the analysis. Next, patients were excluded for the following reasons: 1$)$ incomplete medical records $(n=17,120) ; 2)$ non-general anesthesia $(n=34$, $675)$; 3$)$ use of NMBA other than rocuronium $(n=5645)$; and 4) no NMBA reversal after surgery $(n=4030)$. Therefore, 65,702 patients were included in the final analysis: 4578 in the sugammadex group and 61,124 in the neostigmine group. The mean age of the total patients was 52.3 years with a standard deviation of 15.7. Of the total sample group, 23,532 patients (35.8\%) received general surgery. The proportion of patients receiving emergency surgery was $0.1 \%(72 / 65,702)$. It was further determined that $34,240(52.1 \%)$ patients were ASA physical status 1 and 29,211 (44.5\%) patients were ASA physical status 2 .

After 1:5 PS matching, 3906 and 10,273 patients were isolated in the sugammadex and neostigmine groups, yielding a total of 14,179 patients (Fig. 1). There is a difference between the intended matching ratio (1:5) and actual matching ratio (approximately $1: 2.6$ ) because the matching algorithm was set to nearest neighbor method with a caliper of 0.2. The results of a comparison of the patients' baseline characteristics before and after PS matching is presented in Table 1. The ASD between the two groups after PS matching was well-balanced (ASD < 0.2 ; Table 1). Figure S1 show that the PS distribution was similar in the two groups after PS matching. Additionally, the mean sugammadex dosage was $3.24 \mathrm{mg} / \mathrm{kg}$ with a standard deviation of $0.72 \mathrm{mg} / \mathrm{kg}$, and the mean neostigmine dosage was $30.9 \mathrm{mcg} / \mathrm{kg}$ with a standard deviation of $9.3 \mathrm{mcg} / \mathrm{kg}$.

\section{Ninety-day mortality after non-cardiac surgery}

The results of survival analysis for 90-day mortality before and after PS matching are presented in Table 2 . 


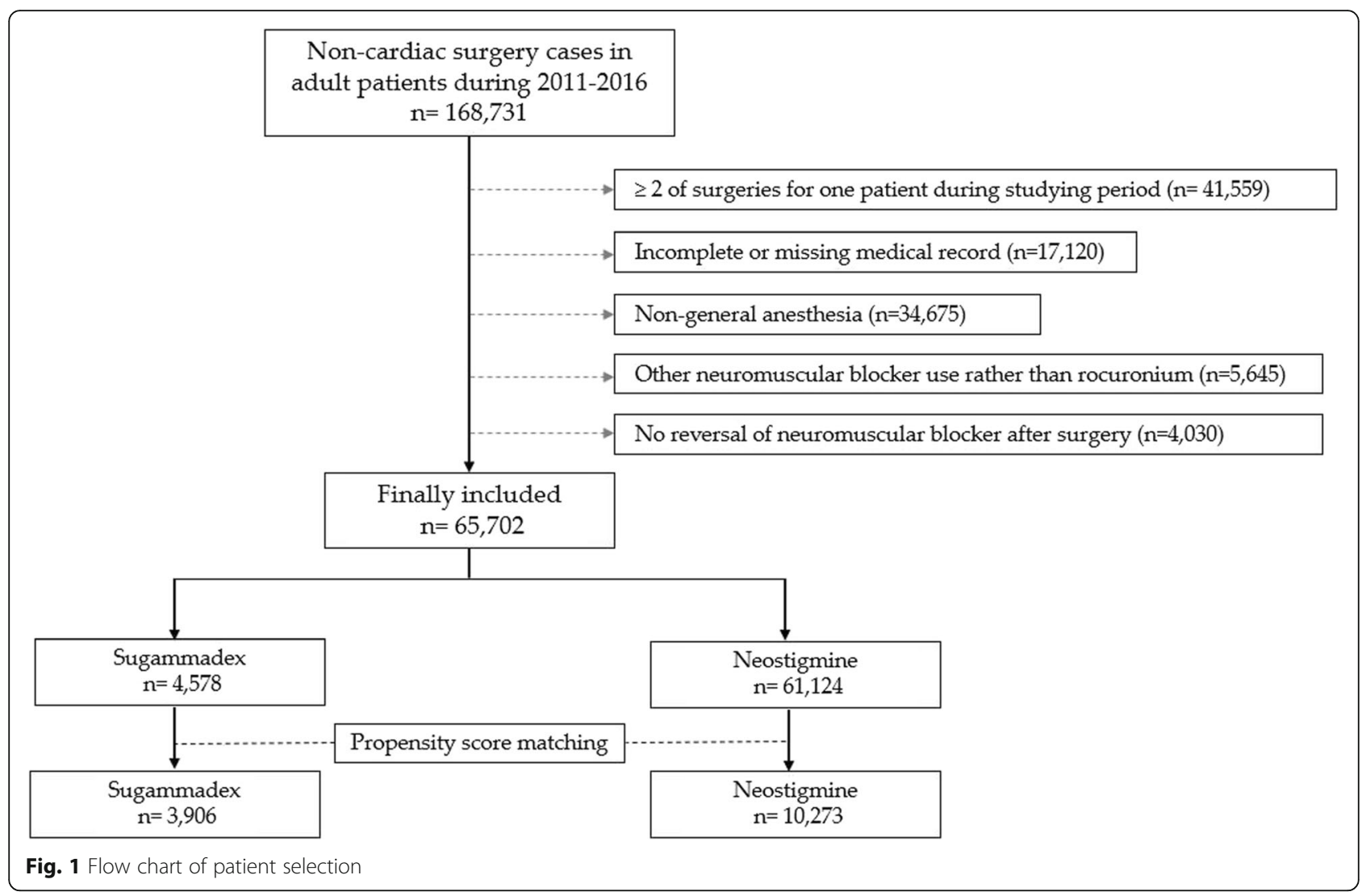

The 90-day mortality in the sugammadex and neostigmine group was $0.6 \%(26 / 4578)$ and $0.6 \%(365 / 61,124)$, respectively, before PS matching in the entire cohort. The Cox regression and logistic regression models showed no statistically significant difference in 90-day mortality between the two groups in the entire cohort ( $P=0.806$ and $P=0.804$, respectively). However, after PS matching, the 90-day mortality in the sugammadex group and neostigmine group was $0.5 \%(20 / 3906)$ and $0.8 \%(87 / 10,273)$, respectively. The Cox regression and logistic regression models showed that use of sugammadex was associated with a $40 \%$ lower 90 -day mortality risk than use of neostigmine (HR: 0.60, 95\% CI: 0.37, 0.98; $P=0.042$ and OR: $0.60,95 \%$ CI: $0.37,0.98 ; P=$ 0.042). In the multivariable Cox regression model in entire cohort, use of sugammadex was also associated with $38 \%$ lower 90-day mortality risk than use of neostigmine (HR: 0.62, 95\% CI: 0.39, 0.96; $P=0.036$; Table 3 ).

\section{Subgroup analysis according to dosage of sugammadex and neostigmine}

Table 4 shows the results of subgroup analysis for 90day mortality according to dosage of neostigmine and sugammadex. In the multivariable Cox regression model in the neostigmine group, when compared to the Q1 group, the Q2, Q3 and Q4 groups were not associated with increased 90-day mortality (all $P>0.05$ ). In the multivariable Cox regression model in the sugammadex group, when compared to the Q1 group, the Q2, Q3 and Q4 groups were not associated with increased 90-day mortality (all $P>0.05$ ).

\section{Discussion}

The results of this retrospective cohort study suggested that reversing rocuronium with sugammadex is associated with a lower 90-day mortality rate after non-cardiac surgery when compared with neostigmine. This association was statistically significant in the PS-matched cohort, but not in the entire cohort. Additionally, the dosage of sugammadex or neostigmine in both groups was not associated with 90-day mortality in subgroup analyses.

The 90 -day mortality rate $(0.6 \%)$ after surgery was relatively lower in this study than that reported in a previous study ( $4 \%$ hospital mortality after surgery) [18]. This difference might be caused by the characteristics of the surgical population of our study. We excluded relatively high-risk patients who underwent 
Table 1 Comparison between sugammadex group and neostigmine group before and after propensity score matching

\begin{tabular}{|c|c|c|c|c|c|c|}
\hline \multirow[t]{3}{*}{ Variables } & \multicolumn{2}{|c|}{ Before PS matching $(n=65,702)$} & \multirow{3}{*}{ ASD } & \multicolumn{2}{|c|}{ After PS matching $(n=14,179)$} & \multirow{3}{*}{ ASD } \\
\hline & Sugammadex & Neostigmine & & Sugammadex & Neostigmine & \\
\hline & $n=4578$ & $n=61,124$ & & $n=3906$ & $n=10,273$ & \\
\hline Age, yr & $57.7(14.3)$ & $51.8(15.7)$ & 0.41 & $57.2(14.5)$ & $55.1(14.9)$ & 0.10 \\
\hline Sex: male & $2738(59.8)$ & $26,517(43.4)$ & 0.34 & $2269(58.1)$ & $5045(49.1)$ & 0.14 \\
\hline Body mass index, $\mathrm{kg} \mathrm{m}^{-2}$ & $24.2(3.5)$ & $24.0(3.4)$ & 0.06 & $24.1(3.5)$ & $24.0(3.4)$ & 0.01 \\
\hline Insurance type & & & 0.03 & & & $<0.01$ \\
\hline National health insurance program & $4488(98.0)$ & $59,706(97.7)$ & & $3822(97.8)$ & $10,045(97.8)$ & \\
\hline Medical aid beneficiary program & $90(2.0)$ & $1418(2.3)$ & & $84(2.2)$ & $228(2.2)$ & \\
\hline Marital status & & & 0.14 & & & 0.04 \\
\hline Never married & $268(5.9)$ & $6892(11.3)$ & & $230(5.9)$ & $784(7.6)$ & \\
\hline Married or living together & 3965 (86.6) & $49,956(81.7)$ & & $3379(86.5)$ & $8722(84.9)$ & \\
\hline Divorced or separated & $119(2.6)$ & $1698(2.8)$ & & $104(2.7)$ & $268(2.6)$ & \\
\hline Widowed & $226(4.9)$ & $2578(4.2)$ & & $193(4.9)$ & $499(4.9)$ & \\
\hline Highest educational attainment & & & 0.07 & & & 0.03 \\
\hline Lower than high school & $1066(23.3)$ & $13,464(22.0)$ & & $903(23.1)$ & $2219(21.6)$ & \\
\hline More than or equal to high school, lower than college & $1434(31.3)$ & $21,193(34.7)$ & & $1235(31.6)$ & $3340(32.5)$ & \\
\hline More than or equal to college & $2078(45.4)$ & $26,467(43.3)$ & & $1768(45.3)$ & $4714(45.9)$ & \\
\hline Occupation & & & 0.19 & & & 0.09 \\
\hline Office worker & $943(20.6)$ & $10,838(17.7)$ & & $804(20.6)$ & $1988(19.4)$ & \\
\hline Licensed job & $448(9.8)$ & $6188(10.1)$ & & $378(9.7)$ & $1046(10.2)$ & \\
\hline House work & $1099(24.0)$ & $19,753(32.3)$ & & $962(24.6)$ & $2996(29.2)$ & \\
\hline Self-employed & $668(14.6)$ & $7114(11.6)$ & & $550(14.1)$ & $1325(12.9)$ & \\
\hline Student, military, or laborer & $454(9.9)$ & 8954 (14.6) & & $384(9.8)$ & $1150(11.2)$ & \\
\hline Unemployed & $966(21.1)$ & $8277(13.5)$ & & $828(21.2)$ & $1768(17.2)$ & \\
\hline \multicolumn{7}{|l|}{ Preoperative comorbidities } \\
\hline ASA physical status & & & 0.20 & & & 0.07 \\
\hline 1 & $1891(41.3)$ & $32,349(52.9)$ & & $1632(41.8)$ & $4814(46.9)$ & \\
\hline 2 & $2489(54.4)$ & $26,722(43.7)$ & & $2103(53.8)$ & $5044(49.1)$ & \\
\hline 3 & $196(4.3)$ & 2001 (3.3) & & $169(4.3)$ & $410(4.0)$ & \\
\hline$\geq 4$ & $2(0.0)$ & $52(0.1)$ & & $2(0.1)$ & $5(0.0)$ & \\
\hline Hypertension & $1299(28.4)$ & $13,402(21.9)$ & 0.14 & $1099(28.1)$ & $2519(24.5)$ & 007 \\
\hline Diabetes mellitus & $567(12.4)$ & $5611(9.2)$ & 0.09 & $482(12.3)$ & $1120(10.9)$ & 0.02 \\
\hline Ischemic heart disease & $262(5.7)$ & $2426(4.0)$ & 0.08 & $229(5.9)$ & $531(5.2)$ & 0.03 \\
\hline Cerebrovascular disease & $205(4.5)$ & $2130(3.5)$ & 0.05 & $182(4.7)$ & $418(4.1)$ & 0.04 \\
\hline Liver disease (fatty liver, hepatitis, liver cirrhosis) & $168(3.7)$ & $1405(2.3)$ & 0.07 & $142(3.6)$ & $310(3.0)$ & $<0.01$ \\
\hline Dyslipidemia & $35(0.8)$ & $596(1.0)$ & 0.02 & $32(0.8)$ & $90(0.9)$ & $<0.01$ \\
\hline Chronic kidney disease & $14(0.3)$ & $204(0.3)$ & $<0.01$ & $14(0.4)$ & $51(0.5)$ & 0.01 \\
\hline Cancer & $2695(58.9)$ & $18,651(30.5)$ & 0.58 & $2242(57.4)$ & $5080(49.5)$ & $<0.01$ \\
\hline \multicolumn{7}{|l|}{ Operative Characteristics } \\
\hline Surgery time, min & $150.7(95.1)$ & $111.8(145.6)$ & 0.39 & $148.6(99.4)$ & $131.4(102.2)$ & 0.05 \\
\hline Anesthesia time, min & $190.8(104.8)$ & $150.7(95.1)$ & 0.38 & $188.3(105.4)$ & $169.6(109.0)$ & 0.04 \\
\hline Emergency surgery & $3(0.1)$ & $69(0.1)$ & 0.02 & $2(0.1)$ & $8(0.1)$ & 0.01 \\
\hline Type of non-cardiac surgery & & & 1.23 & & & 0.08 \\
\hline General surgery & $3185(69.6)$ & $20,347(33.3)$ & & $2777(71.1)$ & $5889(57.3)$ & \\
\hline
\end{tabular}


Table 1 Comparison between sugammadex group and neostigmine group before and after propensity score matching (Continued)

\begin{tabular}{|c|c|c|c|c|c|c|}
\hline \multirow[t]{3}{*}{ Variables } & \multicolumn{2}{|c|}{ Before PS matching $(n=65,702)$} & \multirow{3}{*}{ ASD } & \multicolumn{2}{|c|}{ After PS matching $(n=14,179)$} & \multirow{3}{*}{ ASD } \\
\hline & Sugammadex & Neostigmine & & Sugammadex & Neostigmine & \\
\hline & $n=4578$ & $n=61,124$ & & $n=3906$ & $n=10,273$ & \\
\hline Thoracic surgery & $40(0.9)$ & $2974(4.9)$ & & $40(1.0)$ & $214(2.1)$ & \\
\hline Neuro or spine surgery & $81(1.8)$ & $6552(10.7)$ & & $81(2.1)$ & $461(4.5)$ & \\
\hline Orthopedic surgery & $52(1.1)$ & $8654(14.2)$ & & $52(1.3)$ & $440(4.3)$ & \\
\hline Plastic, ENT, Dental, Eye surgery & $102(2.2)$ & $10,458(17.1)$ & & $128(3.0)$ & $639(6.2)$ & \\
\hline Gynecologic or Urologic surgery & $1128(24.5)$ & $12,139(19.9)$ & & $838(21.5)$ & $2630(25.6)$ & \\
\hline Intraoperative rocuronium dosage, mg & & & 1.26 & & & 0.02 \\
\hline$<50$ & $3(0.1)$ & $130(0.2)$ & & $3(0.1)$ & $11(0.1)$ & \\
\hline $50-100$ & $1082(23.6)$ & $47,049(77.0)$ & & $1080(27.6)$ & $5145(50.1)$ & \\
\hline$>100$ & $3493(76.3)$ & $13,945(22.8)$ & & $2823(72.3)$ & $5117(49.8)$ & \\
\hline Intraoperative qualitative neuromuscular monitoring & $78(1.7)$ & $1.199(2.0)$ & 0.02 & $57(1.5)$ & $128(1.2)$ & 0.01 \\
\hline Year of surgery & & & 1.83 & & & 0.09 \\
\hline 2011-2012 & $0(0.0)$ & $22,198(36.3)$ & & $0(0.0)$ & $776(7.6)$ & \\
\hline 2013-2014 & $475(10.4)$ & $18,215(29.8)$ & & $475(12.2)$ & $2156(21.0)$ & \\
\hline 2015-2016 & $4103(89.6)$ & 20,711 (33.9) & & $3431(87.8)$ & $7341(71.5)$ & \\
\hline
\end{tabular}

Presented as number (percentage) or mean (standard deviation)

PS propensity score; ASD Absolute value of standardized mean difference; ASA American Society of Anesthesiologists; TOF train-of-four

cardiac surgery, and patients who did not receive NMBA reversal in order to receive mechanical ventilation in the intensive care unit (ICU) during the immediate postoperative period. Additionally, the patients with end-stage renal disease might have been excluded from this study, because they usually received atracurium or cisatracurium, rather than rocuronium, during surgery.

When interpreting the present findings, consideration must be given to the fact that both quantitative and qualitative neuromuscular function monitoring was not routine practice, it was performed at the discretion of the attending anesthesiologists. Hence, our data reflects the results of our everyday clinical practice rather than standardized best practice. Previous surveys also have shown the limited use of a neuromuscular monitoring, the majority of which comprised qualitative monitoring, while the use of quantitative monitoring was far less common [19-21]. In this study, we measured the TOF count after surgery at emergence using qualitative rather than quantitative neuromuscular monitoring, because quantitative neuromuscular monitoring at the end of surgery was not available during the study period (2011-2016). Given that quantitative and objective neuromuscular monitoring is considered the gold standard to detect PORC $[3,22]$, the use of qualitative and subjective neuromuscular monitoring may have affected the results of this study. Although we did not have access to postoperative TOF ratio data, we assume that PORC would have been more frequently associated with neostigmine compared to sugammadex for several reasons. The ability of neostigmine to reverse neuromuscular blockade is limited. Even when the full recommended dose of $70 \mathrm{mcg} / \mathrm{kg}$ is administered at a TOF count of 4 , the recovery has been shown to be unsatisfactory $[23,24]$. Additionally, neostigmine overdose in

Table 2 Survival analysis for 90-day mortality before and after propensity score matching

\begin{tabular}{|c|c|c|c|c|c|}
\hline \multirow[t]{2}{*}{ Model } & \multirow[t]{2}{*}{ Event (\%) } & \multicolumn{2}{|l|}{ Cox regression analysis } & \multicolumn{2}{|c|}{ Logistic regression analysis } \\
\hline & & Hazard ratio $(95 \% \mathrm{Cl})$ & $P$-value & Odds ratio $(95 \% \mathrm{Cl})$ & $P$-value \\
\hline \multicolumn{6}{|c|}{ Before propensity score matching } \\
\hline Neostigmine group & 365 / 61,124 (0.6\%) & 1 & & & \\
\hline Sugammadex group & $26 / 4578(0.6 \%)$ & $0.95(0.64,1.42)$ & 0.806 & $0.95(0.64,1.42)$ & 0.804 \\
\hline \multicolumn{6}{|c|}{ After propensity score matching } \\
\hline Neostigmine group & $87 / 10,273(0.8 \%)$ & 1 & & 1 & \\
\hline Sugammadex group & 20/3906 (0.5\%) & $0.60(0.37,0.98)$ & 0.042 & $0.60(0.37,0.98)$ & 0.042 \\
\hline
\end{tabular}


Table 3 Univariable and multivariable Cox regression model for 90-day mortality in entire cohorts

\begin{tabular}{|c|c|c|c|c|}
\hline \multirow[t]{2}{*}{ Model } & \multicolumn{2}{|l|}{ Univariable model } & \multicolumn{2}{|l|}{ Multivariable model $^{a}$} \\
\hline & Hazard ratio $(95 \% \mathrm{Cl})$ & $P$-value & Hazard ratio $(95 \% \mathrm{Cl})$ & $P$-value \\
\hline Age, yr & $1.07(1.06,1.08)$ & $<0.001$ & $1.03(1.02,1.04)$ & $<0.001$ \\
\hline Sex: male (vs female) & $2.34(1.90,2.88)$ & $<0.001$ & $1.81(1.34,2.43)$ & $<0.001$ \\
\hline Body mass index, $\mathrm{kg} \mathrm{m}^{-2}$ & $0.80(0.78,0.83)$ & $<0.001$ & $0.83(0.80,0.85)$ & $<0.001$ \\
\hline Insurance type: Medical aid beneficiary program & $2.93(1.95,4.39)$ & $<0.001$ & $1.30(0.85,1.98)$ & 0.229 \\
\hline \multicolumn{5}{|l|}{ Marital status } \\
\hline Never married & 1 & $(<0.001)$ & 1 & $(0.191)$ \\
\hline Married or living together & $1.80(1.19,2.73)$ & 0.005 & $0.60(0.37,0.97)$ & 0.038 \\
\hline Divorced or separated & $1.31(0.59,2.92)$ & 0.504 & $0.52(023,1.19)$ & 0.119 \\
\hline Widowed & $3.63(2.16,6.13)$ & $<0.001$ & $0.56(0.31,1.04)$ & 0.065 \\
\hline \multicolumn{5}{|l|}{ Highest educational attainment } \\
\hline Lower than high school & 1 & $(<0.001)$ & 1 & $(0.056)$ \\
\hline More than or equal to high school, lower than college & $0.42(0.33,0.54)$ & $<0.001$ & $0.79(0.61,1.02)$ & 0.065 \\
\hline More than or equal to college & $0.35(0.28,0.45)$ & $<0.001$ & $0.75(0.58,0.97)$ & 0.027 \\
\hline \multicolumn{5}{|l|}{ Occupation } \\
\hline Office worker & 1 & $(<0.001)$ & 1 & $(0.076)$ \\
\hline Licensed job & $0.84(0.46,1.51)$ & 0.553 & $0.88(0.49,1.60)$ & 0.677 \\
\hline House work & $1.36(0.91,2.03)$ & 0.129 & $1.19(0.74,1.91)$ & 0.467 \\
\hline Self-employed & $1.43(0.88,2.31)$ & 0.150 & $0.91(0.56,1.49)$ & 0.716 \\
\hline Student, military, or labourer & $1.81(1.67,2.80)$ & 0.008 & $1.07(0.68,1.68)$ & 0.778 \\
\hline Unemployed & $6.73(4.66,7.91)$ & $<0.001$ & $1.47(0.98,2.21)$ & 0.063 \\
\hline \multicolumn{5}{|l|}{ ASA physical status } \\
\hline 1 & 1 & $(<0.001)$ & 1 & $(<0.001)$ \\
\hline 2 & $7.73(5.42,11.03)$ & $<0.001$ & $5.38(3.69,7.91)$ & $<0.001$ \\
\hline 3 & $54.56(37.43,79.53)$ & $<0.001$ & $21.56(14.02,33.16)$ & $<0.001$ \\
\hline$\geq 4$ & $138.51(61.52,311.82)$ & $<0.001$ & $42.44(17.89,100.66)$ & $<0.001$ \\
\hline Hypertension & $1.71(1.39,2.11)$ & $<0.001$ & $0.66(0.52,0.83)$ & $<0.001$ \\
\hline Diabetes mellitus & $2.29(1.78,2.95)$ & $<0.001$ & $0.97(0.75,1.27)$ & 0.824 \\
\hline Ischemic heart disease & $3.87(2.91,5.14)$ & $<0.001$ & $0.90(0.66,1.23)$ & 0.509 \\
\hline Cerebrovascular disease & $3.02(2.17,4.21)$ & $<0.001$ & $0.90(0.64,1.27)$ & 0.546 \\
\hline Liver disease (fatty liver, hepatitis, liver cirrhosis) & $2.56(1.68,3.90)$ & $<0.001$ & $1.81(1.18,2.76)$ & 0.006 \\
\hline Dyslipidemia & $3.28(1.85,5.82)$ & $<0.001$ & $1.20(0.67,2.15)$ & 0.540 \\
\hline Chronic kidney disease & $8.95(4.91,16.30)$ & $<0.001$ & $1.89(1.02,3.52)$ & 0.045 \\
\hline Cancer & $5.27(4.23,6.56)$ & $<0.001$ & $3.32(2.64,4.17)$ & $<0.001$ \\
\hline Surgery time, hour & $1.01(1.01,1.02)$ & $<0.001$ & $1.01(1.01,1.02)$ & $<0.001$ \\
\hline Anesthesia time, hour & $1.27(1.22,1.32)$ & $<0.001$ & & \\
\hline Emergency surgery & $2.36(0.33,16.78)$ & 0.392 & $1.32(0.20,10.28)$ & 0.727 \\
\hline \multicolumn{5}{|l|}{ Type of non-cardiac surgery } \\
\hline General surgery & 1 & $(<0.001)$ & 1 & $(0.007)$ \\
\hline Thoracic surgery & $2.14(1.53,2.99)$ & $<0.001$ & $1.36(0.97,1.92)$ & 0.079 \\
\hline Neuro or spine surgery & $1.04(0.75,1.43)$ & 0.832 & $1.99(1.38,2.85)$ & $<0.001$ \\
\hline Orthopedic surgery & $0.65(0.46,0.93)$ & 0.017 & $1.41(0.97,2.04)$ & 0.074 \\
\hline Plastic, Ear-nose-throat, Dental, Eye surgery & $0.54(0.38,0.77)$ & 0.001 & $1.31(0.91,1.88)$ & 0.150 \\
\hline Gynecologic or Urologic surgery & $0.67(0.50,0.90)$ & 0.008 & $1.04(0.77,1.42)$ & 0.785 \\
\hline
\end{tabular}


Table 3 Univariable and multivariable Cox regression model for 90-day mortality in entire cohorts (Continued)

\begin{tabular}{|c|c|c|c|c|}
\hline \multirow[t]{2}{*}{ Model } & \multicolumn{2}{|l|}{ Univariable model } & \multicolumn{2}{|l|}{ Multivariable model $^{a}$} \\
\hline & Hazard ratio $(95 \% \mathrm{Cl})$ & $P$-value & Hazard ratio $(95 \% \mathrm{Cl})$ & $P$-value \\
\hline \multicolumn{5}{|l|}{ Year of surgery } \\
\hline $2011-2012$ & 1 & $(0.238)$ & 1 & $(0.076)$ \\
\hline 2013-2014 & $0.95(0.74,1.21)$ & 0.672 & $0.94(0.73,1.21)$ & 0.622 \\
\hline $2015-2016$ & $0.82(0.65,1.04)$ & 0.099 & $0.75(0.58,0.97)$ & 0.029 \\
\hline Intraoperative qualitative neuromuscular monitoring & $0.05(0.00,1.19)$ & 0.064 & $0.00(0.00-)$ & 0.893 \\
\hline Intraoperative Rocuronium dosage, per $1 \mathrm{mg} \mathrm{kg}^{-1}$ & $1.54(1.39,1.70)$ & $<0.001$ & $1.00(0.97,1.03)$ & 0.772 \\
\hline Reversal by Sugammadex (vs neostigmine) & $0.95(0.64,1.42)$ & 0.806 & $0.62(0.39,0.96)$ & 0.036 \\
\hline
\end{tabular}

${ }^{a}$ All covariates were included in multivariable model, except for surgery time to avoid multi-collinearity in multivariable Cox regression model

$\mathrm{Cl}$ confidence interval; ASA American Society of Anesthesiologists; TOF train-of-four

fully recovered patients could result in a reduction of muscle strength.

The contribution of PORC to increased postoperative mortality and morbidity has been well-documented in the literature. In a large retrospective study in 2005, Arbous and colleagues reported that inadequate NMBA reversal is an independent risk factor for increased 24-h postoperative mortality and morbidity [25]. Furthermore, Murphy and colleagues reported that residual block increases life-threatening, critical respiratory events in the postoperative recovery room [9]. Bronsert and colleagues were the first to show that PORC caused by NMBA may affect complications in the immediate postoperative period, as well as long-term mortality after non-cardiac surgery [10]. However, they used data from five Veterans Health Administration hospitals in the United States, from 2003 to 2008; sugammadex was only approved by the Food and Drug Administration in the United States in December 2015. Thus, Bronsert and colleagues were unable to consider the effect of sugammadex. In contrast, our institution (SNUBH) has consistently used sugammadex as a drug for NMBA reversal since 2011.
Thus, our study presents novel data in that we have described the effects of sugammadex on 90-day mortality after non-cardiac surgery.

A recently published study on the post-anesthesia pulmonary complications after use of muscle relaxants (POPULAR) trial reported that use of NMBA in general anesthesia is associated with a risk of postoperative pulmonary complications (PPCs), while NMBA reversal with sugammadex was not significantly associated with PPCs [26]. The results of the POPULAR trial differed from those in our study, and the difference could be explained by a human factor of the anesthetist, because approximately one-third of patients who underwent NMBA monitoring were extubated at a TOF ratio $<0.9$. In this context, reversal of sugammadex was independently associated with a better safety profile. Additionally, two recent meta-analyses concluded that sugammadex not only reversed residual NMBA more rapidly and completely by encapsulation than did the anticholinesterase reversal drug (neostigmine), but it was also associated with a better safety profile, specifically regarding residual NMBA after reversal [27, 28]. The meta-analysis

Table 4 Subgroup analysis for 90-day mortality according to dosage of neostigmine and sugammadex

\begin{tabular}{lll}
\hline Variable & $\begin{array}{l}\text { Multivariable Cox regression model } \\
\text { Hazard ratio }(95 \% \mathrm{Cl})\end{array}$ & $\begin{array}{l}P \text { value } \\
\text { Neostigmine dosage, } \mathrm{mcg} \mathrm{kg}^{-1}(n=61,124)\end{array}$ \\
$\mathrm{Q} 1<27.5(n=15,108)$ & 1 & \\
$27.5 \leq \mathrm{Q} 2<31.8(n=15,464)$ & $0.75(0.53,1.06)$ & 0.102 \\
$31.8 \leq \mathrm{Q} 3<36.4(n=15,582)$ & $0.89(0.63,1.25)$ & 0.491 \\
$36.4 \leq \mathrm{Q} 4(n=14,970)$ & $0.96(0.66,1.42)$ \\
Sugammadex dosage, $\mathrm{mg} \mathrm{kg}^{-1}(n=4578)$ & \\
Q1 $<2.8(n=1214)$ & 1 \\
$2.8 \leq \mathrm{Q} 2<3.1(n=963)$ & $0.94(0.11,7.78)$ \\
$3.1 \leq \mathrm{Q} 3<3.6(n=1278)$ & $2.27(0.34,15.15)$ & 0.853 \\
$3.6 \leq \mathrm{Q} 4(n=1123)$ & $2.91(0.30,27.91)$ & 0.397 \\
\hline
\end{tabular}

All covariates were included in the multivariable model Cl confidence interval 
reported that reversal by sugammadex might lead to a lower incidence of residual NMBA, and related sideeffects, than reversal by neostigmine.

Some plausible mechanisms have been suggested to explain why PORC could result in an increase of various complications beyond the immediate postoperative period [29]. First, PORC and NMBA reversal with high-dose neostigmine is known to be associated with development of hypopharyngeal weakness [30, 31], which could lead to a risk of aspiration and pneumonia, and overall higher rates of PPCs [26, 32, 33]. Furthermore, we recently published an observational study in which we showed that NMBA reversal by sugammadex was associated with lower 30-day unplanned readmission rates, hospital charges, and length of hospital stay after major abdominal surgery [34]. In this study, we showed that reversal by sugammadex, which might be closely related to reduced PORC, could have relatively long-term effects on outcome, beyond the immediate postoperative period. Second, NMBA reversal with neostigmine and anticholinesterases might be associated with increased risk of cardiovascular complications in the high-risk group (age $>70$ years, undergoing vascular surgery, prior history of atrial fibrillation) [29, 35]. Furthermore, a recent cohort study reported that PORC in the post-anesthesia care unit is associated with higher rates of ICU admission [36]. Therefore, the results of our current study suggested that efforts to minimize PORC using sugammadex could result in improvement of fatal outcomes, such as 90 -day mortality.

The results of subgroup analyses regarding dosage of neostigmine and sugammadex were also notable in this study. Although the results of the main analysis showed that sugammadex might be potentially beneficial in lowering 90-day mortality, the results of subgroup analyses showed that the dosage of sugammadex or neostigmine did not affect 90-day mortality in either group. In our institution, the dosage of neostigmine (30-50 $\mathrm{mcg} / \mathrm{kg}$ ) or sugammadex $(2-4 \mathrm{mg} / \mathrm{kg}$ ) was determined following the surgical procedure using a peripheral nerve stimulator, in most cases. These results suggested that although the sugammadex group was associated with a lower 90-day mortality than the neostigmine group, the dosage of the agent received in both groups did not affect the 90-day mortality. This may be because the TOF count was checked after surgery in most cases in order to determine the required dosage of neostigmine or sugammadex.

It is possible that the dosage of the agent received in the neostigmine and sugammadex groups affected the results of the main analysis. $2 \mathrm{mg} / \mathrm{kg}$ of sugammadex was administered when the TOF count was $\geq 1$, and 4 $\mathrm{mg} / \mathrm{kg}$ of sugammadex was administered when the PTC was $\geq 1$. In the neostigmine group, the maximum dose of neostigmine $(50 \mathrm{mcg} / \mathrm{kg}$ ) was used for NMBA reversal if the TOF count was 1 (i.e. a moderate block) at the end of surgery in this study. While doses of sugammadex lower than $2.0 \mathrm{mg} / \mathrm{kg}$ can be sufficient to reverse residual rocuronium-induced neuromuscular block with a TOF ratio of 0.2 , even $70 \mathrm{mcg} / \mathrm{kg}$ of neostigmine cannot reliably reverse a residual neuromuscular block with a TOF ratio of 0.2 within $10 \mathrm{~min}$ [37]. This suggests that the administration of $50 \mathrm{mcg} / \mathrm{kg}$ of neostigmine in this study might have been an insufficient dose to reverse a block with a TOF count of 1 without quantitative monitoring [23, 24]. Therefore, the variation of doses in the sugammadex and the neostigmine groups may not be equipotent, and in the absence of quantitative monitoring, it is possible that the neostigmine group in this study was reversed and extubated using a suboptimal dose of neostigmine.

Our study had a few limitations. First, due to the retrospective nature of the study, the quality and accuracy of the data may not meet the standard required for prospective studies. Second, this is a single center study, which limits the generalizability of the findings. Third, the sugammadex group comprised only $7.0 \%$ of the entire cohort; thus, the sample size was substantially reduced after propensity score matching. Fourth, we did not evaluate the PORC at PACU admission in this study, which could limit the results of this study. Fifth, we could not provide information regarding the patients who suffered from PPCs, due to the retrospective nature of the study. Additionally, we did not provide information regarding the causes of 90-day mortality in this study. Lastly, quantitative neuromuscular monitoring was not performed in the study period at emergence after surgery to determine the type or dosage of NMBA reversal agent. Only qualitative neuromuscular monitoring was performed; however, qualitative monitoringguided neostigmine reversal is no longer recommended due to the risk of PORC $[3,22,38]$. Therefore, our results might have differed if quantitative monitoring was performed to guide the dosage of neostigmine; further study is needed to confirm this.

\section{Conclusions}

This retrospective study showed that the use of sugammadex for rocuronium reversal is associated with a reduced 90-day mortality after non-cardiac surgery. However, since this study did not evaluate quantitative neuromuscular function in the postoperative period due to its retrospective design, the results should be interpreted carefully. Future prospective studies with quantitative neuromuscular monitoring in the postoperative period should be performed to confirm this association. 


\section{Supplementary information}

Supplementary information accompanies this paper at https://doi.org/10. 1186/s12871-020-00962-7.

Additional file 1 Figure S1. Distribution of propensity scores before and after propensity score matching

\section{Abbreviations}

ASD: Absolute value of the standardized mean difference; Cl: Confidence interval; HR: Hazard ratio; IRB: Institutional review board;

NMBA: Neuromuscular blocking agents; OR: Odds ratio; PORC: Postoperative residual curarization; SNUBH: Seoul National University Bundang Hospital

\section{Acknowledgements}

None.

\section{Authors' contributions}

TKO and OAY contributed to the study design, analyzed the data, and drafted the first manuscript. JHR and SWN contributed to the data acquisition and critically revised the manuscript. All authors read and approved the final version of the manuscript.

\section{Funding}

This research did not receive any specific grant from funding agencies in the public, commercial, or not-for-profit sectors.

\section{Availability of data and materials}

The datasets generated and analyzed during the current study are available from the corresponding author on reasonable request.

\section{Ethics approval and consent to participate}

This retrospective cohort study was approved by the institutional review board (IRB) of the Seoul National University Bundang Hospital (SNUBH) (Approval number: B-1809-495-102, approval date: September 7, 2018). Considering the retrospective nature of the study, in which the medical records of patients who had already completed treatment were analyzed, the requirement for obtaining informed consent was waived by the IRB.

\section{Consent for publication}

Not applicable.

\section{Competing interests}

The authors declare that they have no competing interests.

Received: 2 November 2019 Accepted: 17 February 2020

Published online: 20 February 2020

\section{References}

1. Cookson JC, Paton WD. Mechanisms of neuromuscular block. A review article. Anaesth. 1969:24(3):395-416

2. Gray TC, Rees GJ. The role of apnoea in anaesthesia for major surgery. $\mathrm{Br}$ Med J. 1952;2(4790):891-2.

3. Naguib M, Kopman AF, Ensor JE. Neuromuscular monitoring and postoperative residual curarisation: a meta-analysis. Br J Anaesth. 2007;98(3): 302-16.

4. Berg H, Roed J, Viby-Mogensen J, Mortensen CR, Engbaek J, Skovgaard LT, Krintel JJ. Residual neuromuscular block is a risk factor for postoperative pulmonary complications. A prospective, randomised, and blinded study of postoperative pulmonary complications after atracurium, vecuronium and pancuronium. Acta Anaesthesiol Scand. 1997;41(9):1095-103.

5. Fortier LP, McKeen D, Turner K, de Medicis E, Warriner B, Jones PM, Chaput A, Pouliot JF, Galarneau A. The RECITE study: a Canadian prospective, multicenter study of the incidence and severity of residual neuromuscular blockade. Anesth Analg. 2015;121(2):366-72

6. Saager L, Maiese EM, Bash LD, Meyer TA, Minkowitz H, Groudine S, Philip BK, Tanaka P, Gan TJ, Rodriguez-Blanco Y, et al. Incidence, risk factors, and consequences of residual neuromuscular block in the United States: the prospective, observational, multicenter RECITE-US study. J Clin Anesth. 2019. 55:33-41.
7. Beecher HK, Todd DP. A study of the deaths associated with anesthesia and surgery: based on a study of 599, 548 anesthesias in ten institutions 19481952, inclusive. Ann Surg. 1954;140(1):2-35.

8. Grosse-Sundrup M, Henneman JP, Sandberg WS, Bateman BT, Uribe JV, Nguyen NT, Ehrenfeld JM, Martinez EA, Kurth T, Eikermann M. Intermediate acting non-depolarizing neuromuscular blocking agents and risk of postoperative respiratory complications: prospective propensity score matched cohort study. BMJ. 2012;345:e6329.

9. Murphy GS, Szokol JW, Marymont JH, Greenberg SB, Avram MJ, Vender JS Residual neuromuscular blockade and critical respiratory events in the postanesthesia care unit. Anesth Analg. 2008;107(1):130-7.

10. Bronsert MR, Henderson WG, Monk TG, Richman JS, Nguyen JD, Sum-Ping JT, Mangione MP, Higley B, Hammermeister KE. Intermediate-acting nondepolarizing neuromuscular blocking agents and risk of postoperative 30-day morbidity and mortality, and long-term survival. Anesth Analg. 2017; 124(5):1476-83.

11. Gijsenbergh F, Ramael S, Houwing N, van lersel T. First human exposure of org 25969, a novel agent to reverse the action of rocuronium bromide. Anesthesiol. 2005;103(4):695-703.

12. Nicholson WT, Sprung J, Jankowski CJ. Sugammadex: a novel agent for the reversal of neuromuscular blockade. Pharmacother. 2007;27(8):1181-8.

13. Shields M, Giovannelli M, Mirakhur RK, Moppett I, Adams J, Hermens Y. Org 25969 (sugammadex), a selective relaxant binding agent for antagonism of prolonged rocuronium-induced neuromuscular block. Br J Anaesth. 2006; 96(1):36-43.

14. Bruintjes MH, van Helden EV, Braat AE, Dahan A, Scheffer GJ, van Laarhoven CJ, Warle MC. Deep neuromuscular block to optimize surgical space conditions during laparoscopic surgery: a systematic review and metaanalysis. Br J Anaesth. 2017;118(6):834-42

15. Brueckmann B, Sasaki N, Grobara P, Li MK, Woo T, de Bie J, Maktabi M, Lee J, Kwo J, Pino R, et al. Effects of sugammadex on incidence of postoperative residual neuromuscular blockade: a randomized, controlled study. $\mathrm{Br}\rfloor$ Anaesth. 2015;115(5):743-51.

16. Brull SJ, Kopman AF. Current status of neuromuscular reversal and monitoring: challenges and opportunities. Anesthesiol. 2017;126(1):173-90.

17. Rubin DB, Thomas N. Matching using estimated propensity scores: relating theory to practice. Biometrics. 1996;52(1):249-64

18. Pearse RM, Moreno RP, Bauer P, Pelosi P, Metnitz P, Spies C, Vallet B, Vincent J, Hoeft A, Rhodes A, et al. Mortality after surgery in Europe: a 7 day cohort study. Lancet. 2012;380(9847):1059-65.

19. Phillips S, Stewart PA, Bilgin AB. A survey of the management of neuromuscular blockade monitoring in Australia and New Zealand. Anaesth Intensive Care. 2013;41(3):374-9.

20. Naguib M, Kopman AF, Lien CA, Hunter JM, Lopez A, Brull SJ. A survey of current management of neuromuscular block in the United States and Europe. Anesth Analg. 2010;111(1):110-9.

21. Grayling M, Sweeney BP. Recovery from neuromuscular blockade: a survey of practice. Anaesth. 2007;62(8):806-9

22. Unterbuchner C, Blobner M, Puhringer F, Janda M, Bischoff S, Bein B, Schmidt A, Ulm K, Pithamitsis V, Fink H. Development of an algorithm using clinical tests to avoid post-operative residual neuromuscular block. BMC Anesthesiol. 2017;17(1):101

23. Kirkegaard H, Heier T, Caldwell JE. Efficacy of tactile-quided reversal from cisatracurium-induced neuromuscular block. Anesthesiol. 2002;96(1):45-50.

24. Kim KS, Cheong MA, Lee HJ, Lee JM. Tactile assessment for the reversibility of rocuronium-induced neuromuscular blockade during propofol or sevoflurane anesthesia. Anesth Analg. 2004:99(4):1080-5.

25. Arbous MS, Meursing AE, van Kleef JW, de Lange JJ, Spoormans HH, Touw $P$, Werner FM, Grobbee DE. Impact of anesthesia management characteristics on severe morbidity and mortality. Anesthesiol. 2005;102(2): 257-68 quiz 491-252.

26. Kirmeier E, Eriksson LI, Lewald H, Jonsson Fagerlund M, Hoeft A, Hollmann M, Meistelman C, Hunter JM, UIm K, Blobner M, et al. Post-anaesthesia pulmonary complications after use of muscle relaxants (POPULAR): a multicentre, prospective observational study. Lancet Respir Med. 2019;7(2): 129-40.

27. Abad-Gurumeta A, Ripolles-Melchor J, Casans-Frances R, Espinosa A Martinez-Hurtado E, Fernandez-Perez C, Ramirez JM, Lopez-Timoneda F, Calvo-Vecino JM. Evidence Anaesthesia review G: a systematic review of sugammadex vs neostigmine for reversal of neuromuscular blockade. Anaesth. 2015;70(12):1441-52. 
28. Hristovska AM, Duch P, Allingstrup M, Afshari A. The comparative efficacy and safety of sugammadex and neostigmine in reversing neuromuscular blockade in adults. A Cochrane systematic review with meta-analysis and trial sequential analysis. Anaesth. 2018;73(5):631-41.

29. Bose S, Xu X, Eikermann M. Does reversal of neuromuscular block with sugammadex reduce readmission rate after surgery? Br J Anaesth. 2019; 122(3):294-8

30. Herbstreit F, Peters J, Eikermann M. Impaired upper airway integrity by residual neuromuscular blockade: increased airway collapsibility and blunted genioglossus muscle activity in response to negative pharyngeal pressure. Anesthesiol. 2009;110(6):1253-60.

31. Herbstreit F, Zigrahn D, Ochterbeck C, Peters J, Eikermann M. Neostigmine/ glycopyrrolate administered after recovery from neuromuscular block increases upper airway collapsibility by decreasing genioglossus muscle activity in response to negative pharyngeal pressure. Anesthesiol. 2010; 113(6):1280-8

32. Sasaki N, Meyer MJ, Malviya SA, Stanislaus AB, MacDonald T, Doran ME, Igumenshcheva A, Hoang AH, Eikermann M. Effects of neostigmine reversal of nondepolarizing neuromuscular blocking agents on postoperative respiratory outcomes: a prospective study. Anesthesiol. 2014;121(5):959-68.

33. Sauer M, Stahn A, Soltesz S, Noeldge-Schomburg G, Mencke T. The influence of residual neuromuscular block on the incidence of critical respiratory events. A randomised, prospective, placebo-controlled trial. Eur J Anaesthesiol. 2011;28(12):842-8.

34. Oh TK, Oh AY, Ryu JH, Koo BW, Song IA, Nam SW, Jee HJ. Retrospective analysis of 30-day unplanned readmission after major abdominal surgery with reversal by sugammadex or neostigmine. Br J Anaesth. 2019;122(3): 370-8.

35. Shaydenfish D, Scheffenbichler FT, Kelly BJ, Lihn AL, Deng H, Nourmahnad A, Xu X, Houle TT, Eikermann M, Forman SA. Effects of anticholinesterase reversal under general anesthesia on postoperative cardiovascular complications: a retrospective cohort study. Anesth Analg. 2019

36. Grabitz SD, Rajaratnam N, Chhagani K, Thevathasan T, Teja BJ, Deng H, Eikermann M, Kelly BJ. The effects of postoperative residual neuromuscular blockade on hospital costs and intensive care unit admission: a populationbased cohort study. Anesth Analg. 2019;128(6):1129-36.

37. Kaufhold N, Schaller SJ, Stauble CG, Baumuller E, Ulm K, Blobner M, Fink H. Sugammadex and neostigmine dose-finding study for reversal of residual neuromuscular block at a train-of-four ratio of 0.2 (SUNDRO20)dagger. Br J Anaesth. 2016;116(2):233-40.

38. Naguib M, Brull SJ, Kopman AF, Hunter JM, Fulesdi B, Arkes HR, Elstein A, Todd MM, Johnson KB. Consensus statement on perioperative use of neuromuscular monitoring. Anesth Analg. 2018;127(1):71-80.

\section{Publisher's Note}

Springer Nature remains neutral with regard to jurisdictional claims in published maps and institutional affiliations.

Ready to submit your research? Choose BMC and benefit from:

- fast, convenient online submission

- thorough peer review by experienced researchers in your field

- rapid publication on acceptance

- support for research data, including large and complex data types

- gold Open Access which fosters wider collaboration and increased citations

- maximum visibility for your research: over $100 \mathrm{M}$ website views per year

At $\mathrm{BMC}$, research is always in progress.

Learn more biomedcentral.com/submissions 